\title{
Factor Xa as an Interface Between Coagulation and Inflammation Molecular Mimicry of Factor Xa Association with Effector Cell Protease Receptor-1 Induces Acute Inflammation In Vivo
}

\author{
Giuseppe Cirino, ${ }^{*}$ Carla Cicala, ${ }^{*}$ Mariarosaria Bucci, ${ }^{*}$ Ludovico Sorrentino, ${ }^{\star}$ Grazia Ambrosini, ${ }^{\S}$ Gianfranco DeDominicis, ${ }^{\ddagger}$ \\ and Dario C. Altieri ${ }^{\S}$ \\ *Departimento di Farmacologia Sperimentale, Universita’ degli Studi di Napoli “Federico II”, 80131 Napoli, Italy; ${ }^{\ddagger}$ Servizio di Anatomia \\ Patologica, Ospedale Cardarelli 80131 Napoli, Italy; and ${ }^{\S}$ Molecular Cardiobiology Program, The Boyer Center for Molecular Medicine, \\ Department of Pathology, Yale University School of Medicine, New Haven, Connecticut 06536
}

\begin{abstract}
Coagulation proteases were tested in a rat model of acute inflammation. Subplantar injection of Factor Xa (10-30 $\mu \mathrm{g})$ produced a time- and dose-dependent edema in the rat paw, and potentiated carrageenin-induced edema. In contrast, the homologous protease Factor IXa was ineffective. This inflammatory response was recapitulated by the Factor Xa sequence $\mathrm{L}^{83} \mathrm{FTRKL}^{88}(\mathrm{G})$, which mediates ligand binding to effector cell protease receptor-1 (EPR-1), while a control scrambled peptide did not induce edema in vivo. Conversely, injection of the EPR-1-derived peptide $S^{123}$ PGKPGNQNSKNEPP ${ }^{137}$ (corresponding to the receptor binding site for Factor $\mathrm{Xa}$ ) inhibited carrageenin-induced rat paw edema, while the adjacent EPR-1 sequence $P^{136}$ PKKRERERSSHCYP ${ }^{150}$ was without effect. EPR-1-Factor Xa-induced inflammation was characterized by fast onset and prominent perivascular accumulation of activated and degranulated mast cells, was inhibited by the histamine/serotonin antagonists cyproheptadine and methysergide, but was unaffected by the thrombin-specific inhibitor, Hirulog. These findings suggest that through its interaction with EPR-1, Factor Xa may function as a mediator of acute inflammation in vivo. This pathway may amplify both coagulation and inflammatory cascades, thus contributing to the pathogenesis of tissue injury in vivo. (J. Clin. Invest. 1997. 99:2446-2451.) Key words: coagulation • leukocytes • inflammation • Factor Xa • tissue injury
\end{abstract}

\section{Introduction}

It has been appreciated for more than two decades that activation of coagulation is invariably linked to immune-inflammatory responses in vivo. From the earlier histopathological detection of fibrin in delayed-type hypersensitivity (1) and on tissue macrophages (2), recent experiments have demonstrated that systemic defibrinogenation drastically attenuates inflammatory responses to purulent bacterial infections (3),

Address correspondence to Dario C. Altieri, M.D., Yale University School of Medicine, BCMM 436B, 295 Congress Avenue, New Haven, CT 06536. Phone: 203-737-2869; FAX: 203-737-2290; E-mail: Dario.Altieri@yale.edu

Received for publication 19 December 1996 and accepted in revised form 14 March 1997.

J. Clin. Invest.

(C) The American Society for Clinical Investigation, Inc. 0021-9738/97/05/2446/06 \$2.00

Volume 99, Number 10, May 1997, 2446-2451 implanted biomaterials (4), and Ig-mediated acute nephrotoxic nephrites (5) in vivo.

While dysregulation of coagulation contributes to vascular injury (6) and atherosclerosis (7), the molecular basis of the interface between coagulation and inflammation is not completely understood. Recent experimental evidence has suggested that in addition to their role in hemostasis (8), proteases of the clotting and fibrinolytic cascades may also transduce intracellular signals and modulate immune-inflammatory responses (9). Proteolytic activation of the thrombin receptor on leukocytes increased cytosolic free $\mathrm{Ca}^{2+}(10)$, and stimulated MAP kinase activation, protein tyrosine phosphorylation (11), and the release of chemotactic (12) and inflammatory (13) cytokines. Occupancy of the urokinase receptor regulated macrophage adherence (14), gene expression (15), and chemotaxis (16). Finally, consistent with its mitogenic (17) and signaling (18) properties, binding of Factor Xa to effector cell protease receptor-1 (EPR-1) ${ }^{1}$ participated in leukocyte activation (9), brain pericyte- (19), platelet- (20), and endothelial cell-thrombin formation (21), and aortic smooth muscle cell proliferation (22).

In an effort to reinvestigate the interface between coagulation and inflammation, we have found that Factor Xa, but not Factor IXa, induced an acute inflammatory response in vivo, and that this pathway was recapitulated by small synthetic peptides mimicking ligand binding to EPR-1.

\section{Methods}

Coagulation proteins and synthetic peptides. Coagulation Factors IXa and Xa were purchased from Calbiochem Corp. (La Jolla, CA) or Haematologic Technologies (Essex Junction, VT), and used in previous studies. Synthetic peptidyl mimicry of EPR-1 recognition of Factor $\mathrm{Xa}$, as identification of the interacting sequences implicated in ligand binding, was reported previously (21). The partially overlapping peptides AG1 $\left(\mathrm{S}^{123} \mathrm{PGKPGNQNSKNEPP}{ }^{137}\right)$ and AG2 (P ${ }^{136} \mathrm{PKK}-$ RERERSSHCYP ${ }^{150}$ ) were synthesized from the sequence of the A1 chimera in the extracellular domain of EPR-1, containing the receptor binding site for Factor Xa (21). Inhibition of Factor V/Va-independent endothelial cell prothrombin activation by the AG1 peptide, but not by AG2, was as described (21). The identification of the interEGF sequence $\mathrm{L}^{83} \mathrm{FTRKL}^{88}(\mathrm{G})$ in Factor Xa (residue in parentheses added to the natural sequence) as a binding site for EPR-1 based on synthetic peptidyl mimicry, a sequence-specific antibody and gainof-function of a recombinant Factor IX chimera containing the Factor $\mathrm{X}$ sequence $83-88$, was reported previously (23). A scrambled peptide KFTGRLL for the Factor X 83-33 sequence was synthesized and used as a control in these experiments. All peptides were characterized by HPLC and mass spectrometry and dissolved in sterile saline.

1. Abbreviations used in this paper: EPR-1, effector cell protease receptor-1; PAS, periodic acid Schiff. 
Rat paw edema formation. The experimental procedures for agonist-induced edema in vivo have been described previously (24). Briefly, groups of five to six male Wistar rats (Charles River Laboratories, Milano, Italy) weighing $120-150 \mathrm{~g}$ each were lightly anesthetized with enflurane and treated with subplantar injections of sterile saline or various concentrations (1-30 $\mu \mathrm{g}$ ) of Factors IXa, Xa, or the EPR-1- or Factor Xa-derived peptides (10-300 $\mu \mathrm{g})$, in a total volume of $100 \mu \mathrm{l}$. In potentiation experiments, animals were injected with a suboptimal concentration of carrageenin $(0.1 \%, 100 \mu \mathrm{l} / \mathrm{paw})$ simultaneously with concentrations of Factor Xa (1-3 $\mu \mathrm{g})$ which do not cause edema, before evaluation of rat paw edema. To assess the potential contribution of EPR-1 in carrageenin-induced edema, animals were injected with a maximal concentration of carrageenin of $1 \%$ (100 $\mu \mathrm{l} / \mathrm{paw})$ simultaneously with $10-100 \mu \mathrm{g}$ of the EPR-1-derived peptide AG1 or AG2 (21). Paw volume was determined using a hydroplethismometer (Ugo Basile, Milano, Italy) immediately before the subplantar injection of the various agonists, and sequentially at 15min time intervals for the first hour of the experiment, and hourly thereafter for up to $5 \mathrm{~h}$ (carrageenin-induced edema only). The increase in paw volume under the various experimental conditions tested was evaluated as difference between the paw volume at each interval and the basal paw volume (24). In another series of experiments, animals were separately injected intraperitoneally with the histamine/serotonin antagonist cyproheptadine $(5 \mathrm{mg} / \mathrm{kg})$, the serotonin-specific antagonist methysergide $(2 \mathrm{mg} / \mathrm{kg})$, the mast cell aminestabilizing agent cromolyn $(10 \mathrm{mg} / \mathrm{kg})$, or the thrombin-specific inhibitor Hirulog $(5 \mathrm{mg} / \mathrm{kg})(24) 30 \mathrm{~min}$ before administration of the Factor Xa peptide 83-88 $(100 \mu \mathrm{g})$ or Factor Xa $(10 \mu \mathrm{g})$ and determination of changes in rat paw volume. All edema experiments were repeated at least three times with similar results

Histochemistry. Untreated animals, or rats injected with Factor Xa $(10 \mu \mathrm{g})$ or the Factor Xa peptide $83-88$, were killed 15 min after treatment. The paws were removed, fixed in $10 \%$ buffered formalin, demineralized, and tissue samples were embedded in paraffin blocks. 4- $\mu \mathrm{m}$ sections were cut, put on high adhesive slides, and stained with hematoxylin/eosin, periodic acid Schiff (PAS), or Giemsa before counterstaining and examination under light microscopy.

Statistical analysis. All results are reported as mean \pm SEM. The unpaired two-tailed Student's $t$ test was used for statistical evaluation when two groups were compared. When control values were compared to more than one group, ANOVA followed by Dunnett's fort test was used. A value of $P<0.05$ was taken as significant.

\section{Results}

Factor Xa induces acute inflammation in vivo. Subplantar administration of Factor $\mathrm{Xa}$ in rats was associated with a rapid increase in the paw volume, which peaked after 15 min from the injection, and progressively decreased to background levels of control animals injected with saline after a 45-min interval (Fig. $1 A$ ). Edema formation under these experimental conditions was dose-dependent and maximal at $10 \mu \mathrm{g}$ of added Factor $\mathrm{Xa}$, with no additional increase in rat paw volume for Factor Xa concentrations up to $30 \mu \mathrm{g}$ (Fig. $1 A$ ). In contrast, comparable concentrations of the Factor Xa-homologous coagulation protease, Factor IXa, did not significantly increase the rat paw volume under the same experimental conditions (Fig. $1 \mathrm{~A}$ ). The combination of a nonstimulating concentration of Factor Xa $(3 \mu \mathrm{g})$ plus a suboptimal dose $(0.1 \%)$ of carrageenin (25) resulted in a significantly increased rat paw edema when compared with that of control animals treated with carrageenin alone, with a peak response observed $2 \mathrm{~h}$ after injection (Fig. $1 B$ ).

Synthetic peptidyl mimicry of Factor Xa-induced inflammation. Previous experiments demonstrated that the inter-EGF sequence $\mathrm{Leu}^{83}-\mathrm{Leu}^{88}$ in Factor Xa mediates ligand binding to
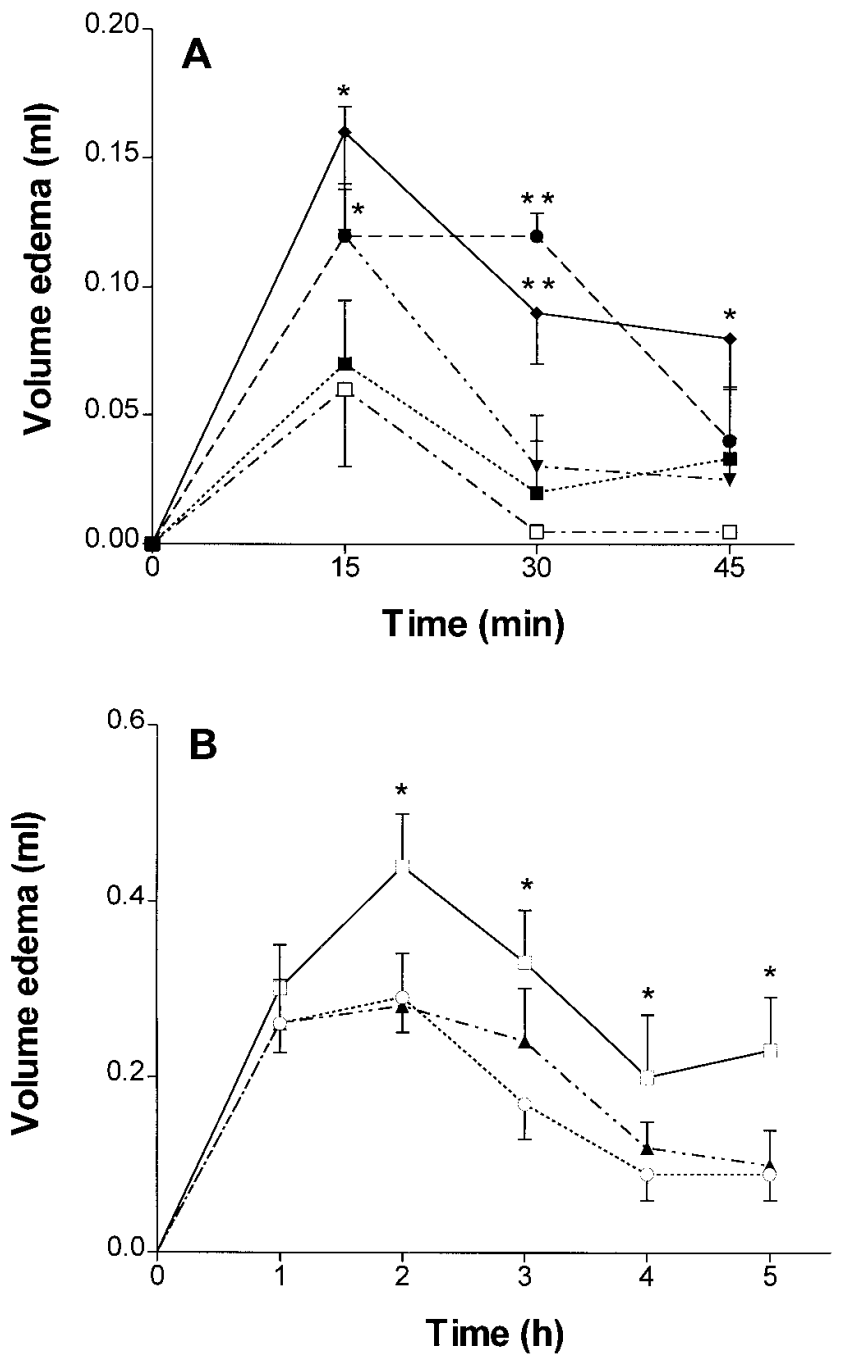

Figure 1. Factor Xa-induced edema in vivo. (A) Groups of five to six animals were injected in the paw with $1 \mu \mathrm{g}(\boldsymbol{\nabla}), 10 \mu \mathrm{g}(\diamond)$, or $30 \mu \mathrm{g}$ (•) Factor Xa, $10 \mu \mathrm{g}$ Factor IXa (ם), or control saline ( $\square$ ), in a total volume of $100 \mu \mathrm{l}$. Edema formation under the various conditions tested was determined using a hydroplethismometer at 15-min intervals from the injection. $(B)$ Animals were injected with a suboptimal concentration of carrageenin $(0.1 \%)$ in the absence $(O)$ or in the presence of $1 \mu \mathrm{g}(\boldsymbol{\Delta})$ or $3 \mu \mathrm{g}(\square)$ Factor Xa, before determination of edema at the indicated time intervals. For both panels, data are the mean \pm SEM of at least three independent experiments.

EPR-1 (23). The possibility that this interacting motif may mimic the inflammatory effect of Factor Xa in vivo was investigated. Administration of the Factor Xa peptide 83-88 produced a dose-dependent edema of the rat paw, which was maximal at $300 \mu \mathrm{g}$ of peptide and peaked $15 \mathrm{~min}$ after injection, remaining sustained for $45-60 \mathrm{~min}$ (Fig. $2 A$ ). In contrast, no statistically significant changes in rat paw volume were observed after injection of $100-\mu \mathrm{g}$ concentrations of a control scrambled peptide of the 83-88 sequence (Fig. $2 \mathrm{~A}$ ). Similar to the potentiating effect of Factor $\mathrm{Xa}$ on carrageenin-induced edema, intravenous administration of the Factor Xa peptide 83$88(3 \mathrm{mg} / \mathrm{kg})$ significantly increased (32-39\%) the magnitude of rat paw edema induced by suboptimal concentrations of carra- 

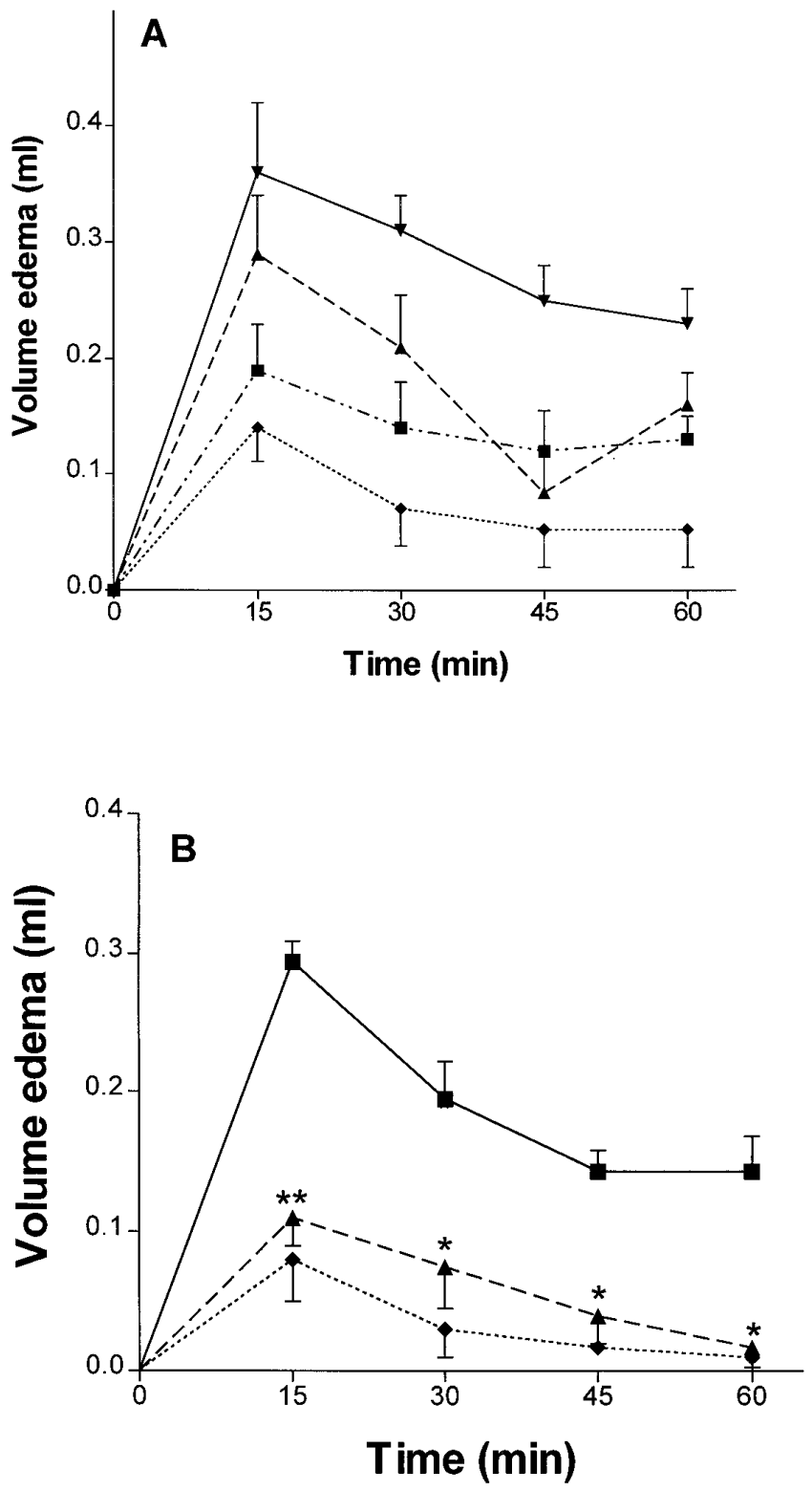

Figure 2. Effect of Factor Xa peptide 83-88 on rat paw edema. (A) Animals were injected with $10 \mu \mathrm{g}(\boldsymbol{\square}), 100 \mu \mathrm{g}(\boldsymbol{\Delta})$, or $300 \mu \mathrm{g}(\boldsymbol{\nabla})$ of the Factor Xa peptide $\mathrm{L}^{83} \mathrm{FTRKL}^{88}(\mathrm{G})$, or with $100 \mu \mathrm{g}$ of control scrambled peptide KFTGRLL $(\diamond)$, and paw edema was determined at the indicated time intervals. (B) Animals were injected with $100 \mu \mathrm{g}$ of the Factor Xa peptide 83-88 in the absence ( $\mathbf{\square})$ or in the presence of the histamine/serotonin antagonist cyproheptadine $(\bullet)$, or the serotonin-specific antagonist methysergide $(\boldsymbol{\Lambda})$, before determination of paw edema at the indicated time intervals.

geenin at 3 and $4 \mathrm{~h}$ after injection, respectively (not shown). The mechanism(s) of Factor Xa-induced inflammation was investigated. First, in vivo administration of the serotonin/histamine antagonist cyproheptadine or the serotonin antagonist methysergide inhibited rat paw edema induced by the Factor Xa peptide 83-88 at all time points examined (Fig. 2 B). A partial reduction in edema formation was also observed after administration of the mast cell amine stabilizer cromolyn (not shown). In contrast, injection of the thrombin-specific inhibi- tor Hirulog $(5 \mathrm{mg} / \mathrm{kg})$ did not reduce the magnitude or the duration of rat paw edema induced by $10 \mu \mathrm{g}$ Factor Xa (not shown), while it inhibited thrombin-dependent edema in vivo (24).

Morphologic analysis of Factor Xa-induced inflammation in vivo. Histochemical analysis of hematoxylin/eosin staining of the rat paw injected with Factor Xa or the Factor Xa peptide 83-88 revealed a complete disruption of tissue architecture and loss of organization characteristic of interstitial edema (24), as compared with control tissue sections of untreated animals (Fig. 3, $A-C$ ). Relevant histological features of the inflammatory response induced by Factor Xa or the Factor Xa peptide 83-88 included prominent perivascular accumulation of activated and partially degranulated mast cells and fibroblasts identified by PAS and Giemsa staining (Fig. 3, D and $E$, arrows, insets).

Participation of EPR-1 in acute inflammatory responses in vivo. A potential accessory role of EPR-1 in carrageenininduced edema in vivo was investigated. Administration of increasing concentrations of the functionally blocking EPR-1derived peptide AG1 S ${ }^{123}$ PGKPGNQNSKNEPP ${ }^{137}$ (21) inhibited in a dose-dependent manner carrageenin-induced rat paw edema at 2- and 3-h intervals (Fig. 4). In contrast, comparable concentrations of the adjacent EPR-1 sequence AG2 P136 PKKRERERSSHCYP ${ }^{150}$ did not reduce carrageenin-induced edema under the same experimental conditions (Fig. 4).

\section{Discussion}

In this study, we have shown that Factor $\mathrm{Xa}$, but not the homologous protease Factor IXa, induced an acute inflammatory response in the rat paw, and potentiated carrageenin-induced edema in vivo. This pathway was mediated by binding of Factor Xa to its cellular receptor EPR-1 (26), as judged by the ability of small synthetic peptides mimicking this interaction to induce inflammation and modulate carrageenin-induced edema, in vivo.

Compelling experimental and clinical evidence suggests that coagulation and inflammation are intimately connected processes $(6,27)$. While the participation of leukocytes in coagulation has been extensively demonstrated and recognized as a major pathogenetic risk factor in vascular diseases (7), recent experimental findings have also identified a direct role of clotting and fibrinolytic proteases in intracellular signal transduction and modulation of inflammatory cell responses. This concept was further reinforced by the recent identification of various cellular protease receptors as modulators of second messengers $(11,18)$, cytokine gene expression $(12,15)$, and white blood cell motility (16). In this context, the vascular Factor Xa receptor EPR-1 (26) has been characterized for its role in platelet- (20), brain pericyte- (19), and endothelial cellthrombin formation (21), leukocyte activation (9), and smooth muscle cell proliferation (22). Here, binding of Factor Xa to EPR-1 resulted in a novel nonhemostatic function of this protease, i.e., the induction of an acute inflammatory response in vivo. The molecular basis of this pathway appears to reside in the ability of Factor Xa to promote recruitment of mast cells and rapid discharge of vasoactive mediators, as judged by the prominent perivascular accumulation of activated and partially degranulated mast cells in situ, and by the inhibition of edema formation by histamine/serotonin antagonists. Consistent with this model, anti-EPR-1 mAbs B6 and 12H1 prominently re- 

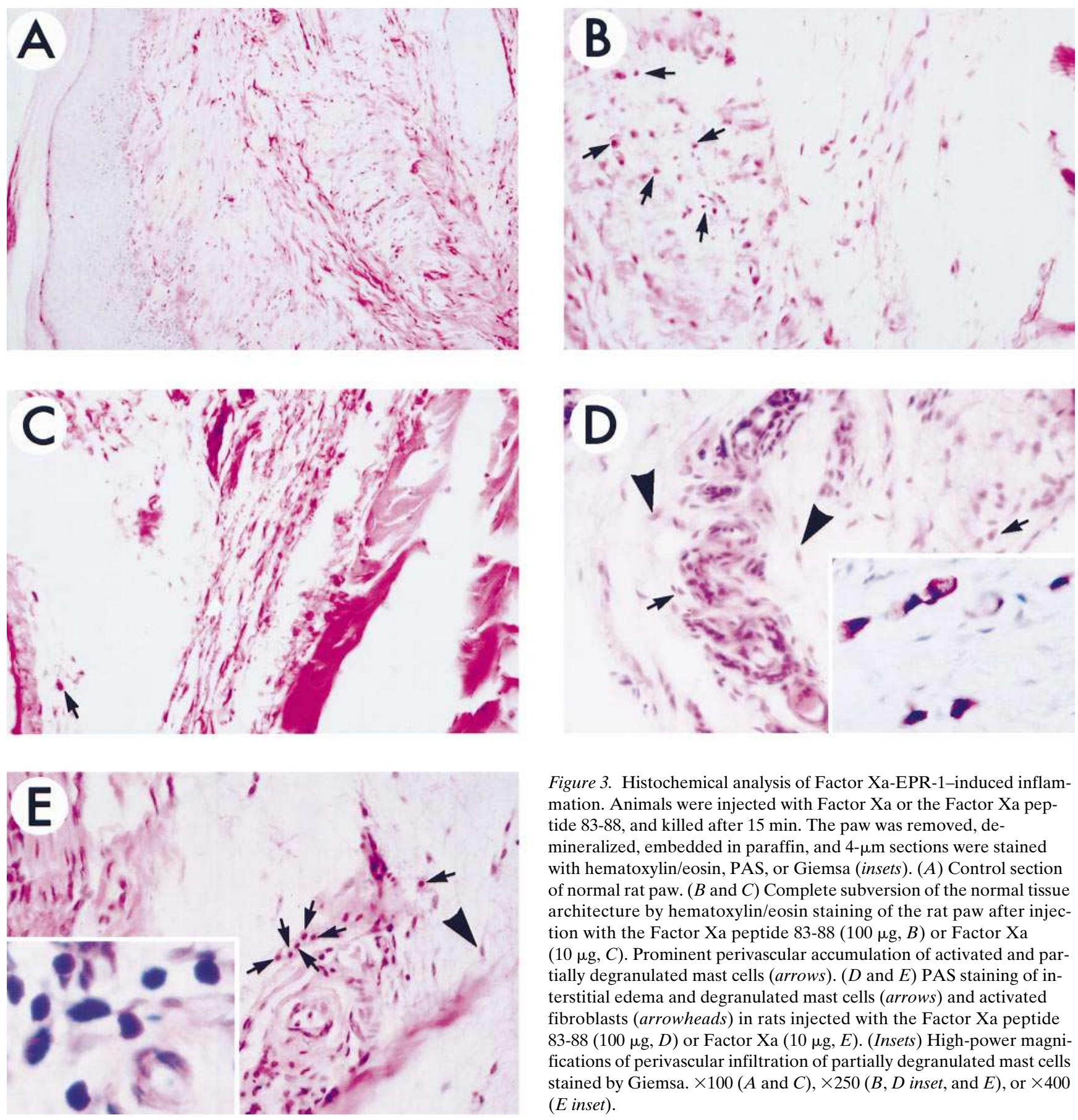

Figure 3. Histochemical analysis of Factor Xa-EPR-1-induced inflammation. Animals were injected with Factor Xa or the Factor Xa peptide 83-88, and killed after $15 \mathrm{~min}$. The paw was removed, demineralized, embedded in paraffin, and $4-\mu \mathrm{m}$ sections were stained with hematoxylin/eosin, PAS, or Giemsa (insets). (A) Control section of normal rat paw. ( $B$ and $C$ ) Complete subversion of the normal tissue architecture by hematoxylin/eosin staining of the rat paw after injection with the Factor Xa peptide 83-88 $(100 \mu \mathrm{g}, B)$ or Factor Xa $(10 \mu \mathrm{g}, C)$. Prominent perivascular accumulation of activated and partially degranulated mast cells (arrows). ( $D$ and $E$ ) PAS staining of interstitial edema and degranulated mast cells (arrows) and activated fibroblasts (arrowheads) in rats injected with the Factor Xa peptide 83-88 $(100 \mu \mathrm{g}, D)$ or Factor Xa $(10 \mu \mathrm{g}, E)$. (Insets) High-power magnifications of perivascular infiltration of partially degranulated mast cells stained by Giemsa. $\times 100(A$ and $C), \times 250(B, D$ inset, and $E)$, or $\times 400$ (E inset).

acted with murine MC/9 mast cells by flow cytometry (our unpublished observations). At variance with the paradigm of protease-activated receptors $(5,28)$, but analogous to the recognition of the urokinase receptor (29), the interaction of Factor Xa with the A1 extracellular region of EPR-1 (21) did not require an intact catalytic active site in the ligand. Rather, EPR-1 recognition of Factor Xa was mediated by the interEGF sequence $\mathrm{Leu}^{83}-\mathrm{Leu}^{88}$, which acquired receptor binding specificity in the active protease, but not in the zymogen Factor X (23). Accordingly, this peptide sequence recapitulated the pathway of Factor Xa-mediated inflammation, inducing rat paw edema and accumulation of activated and degranu- lated mast cells in situ. While Factor Xa modulation of vascular cell gene expression and aortic smooth muscle cell proliferation required binding to EPR-1 followed by a secondary step of ligand-dependent proteolysis (22), other signaling events can be directly triggered by physical receptor occupancy, as shown by the ability of anti-EPR-1 mAbs to increase cytosolic $\mathrm{Ca}^{2+}$ in isolated $\mathrm{T}$ cells and to potentiate mononuclear cell proliferation (9).

The inability of the thrombin-specific antagonist Hirulog (24) to affect Factor Xa-induced inflammation in vivo confirmed the specificity of this pathway, and ruled out a potential participation of downstream activation of coagulation. On the 


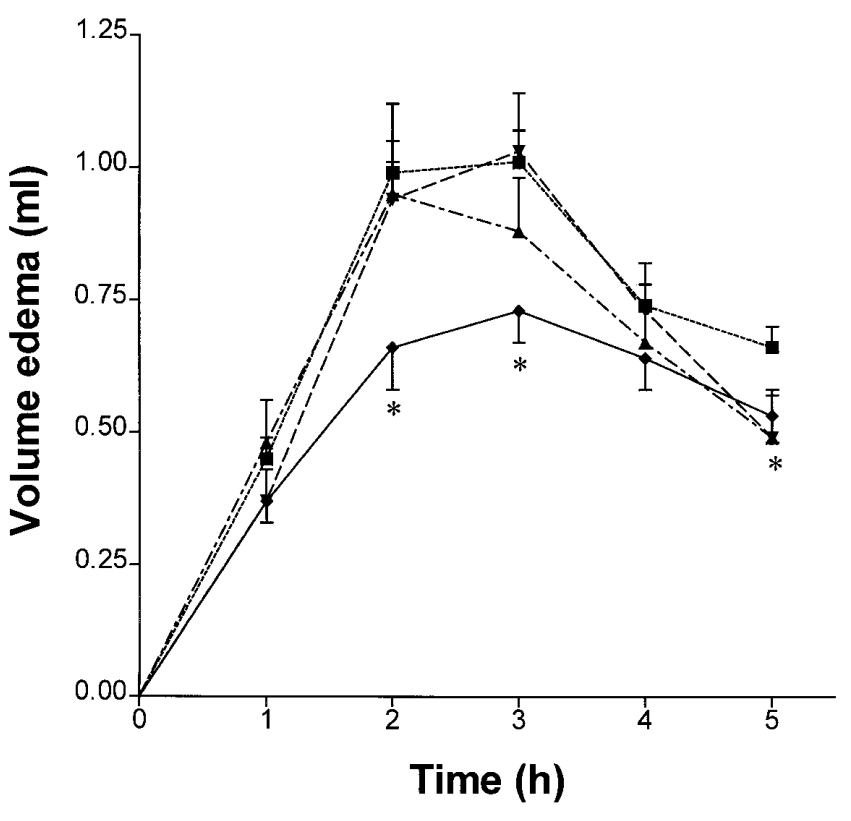

Figure 4. Participation of EPR-1 in carrageenin-induced edema in vivo. Animals were injected with $1 \%$ carrageenin simultaneously with $10 \mu \mathrm{g}(\boldsymbol{\nabla}), 30 \mu \mathrm{g}(\boldsymbol{\Delta})$, or $100 \mu \mathrm{g}(\boldsymbol{)})$ of the EPR-1-derived AG1 peptide ${ }^{123}$ PGKPGNQNSKNEPP ${ }^{137}$, or $100 \mu \mathrm{g}(\mathbf{\square})$ of EPR-1-derived AG2 peptide $\mathrm{P}^{136} \mathrm{PKKRERERSSHCYP}{ }^{150}$, before determination of paw edema at the indicated time intervals. Data are the mean \pm SEM of three independent experiments.

other hand, the ability of the EPR-1-Factor Xa interaction to enhance prothrombin activation on several vascular and perivascular cell types $(19,20,23,26)$ may provide an additional mechanism to potentiate this inflammatory response in vivo. Increase in vascular permeability (25) with extravasation of coagulation zymogens may favor monocyte/macrophage activation of Factor X to Xa (30) in a localized membrane microenvironment, with enhanced inflammation by Factor $\mathrm{Xa}$ (this study) or thrombin (24), generated through the EPR-1 pathway. In this context, the EPR-1-derived AG1 peptide, which comprised the receptor binding sequence for Factor Xa and inhibited EPR-1-dependent prothrombin activation (21), significantly reduced carrageenin-induced edema in vivo.

The potential pathophysiological relevance of these observations is reflected in the pivotal role of leukocytes in vascular injury and atherosclerosis (7). As a target of the Factor XaEPR-1 pathway described here, mast cells $(31,32)$ are ideally positioned to initiate and amplify a broad range of vascular and inflammatory cell responses, including acute angioedema or urticaria. Mast cell release of inflammatory mediators like histamine/serotonin, leukotrienes, PAF, and cytokines, triggers increased vascular permeability, enhanced leukocyte activation (33), upregulation of $\beta_{2}$ integrin function (34), and increased leukocyte rolling and adherence to endothelium (35, 36), thus further exacerbating tissue injury and disruption of the endothelial cell monolayer (7).

In summary, by mimicking the EPR-1 recognition of Factor Xa (26), we have identified a novel molecular interface between inflammation and coagulation that may contribute to vascular and tissue injury in vivo. Antagonists of this pathway, like the EPR-1-derived AG1 peptide (21), may prove benefi- cial to selectively target the inflammatory functions of blood proteases in vivo without affecting their normal hemostatic properties.

\section{Acknowledgments}

We thank Ciro Chiaiese for excellent technical assistance.

This work was supported by National Institutes of Health grants HL-43773 and HL-54131. This work was done during the tenure of an Established Investigatorship Award from the American Heart Association to Dr. Altieri.

\section{References}

1. Colvin, R.B., R.A. Johnson, M.C. Mihm, Jr., and H.F. Dvorak. 1973. Role of the clotting system in cell-mediated hypersensitivity. I. Fibrin deposition in delayed skin reactions in man. J. Exp. Med. 138:686-698.

2. Sherman, L., and J. Lee. 1977. Specific binding of soluble fibrin to macrophages. J. Exp. Med. 145:76-85.

3. McRitchie, D.I., M.J. Girotti, M.F.X. Glynn, J.M. Goldberg, and O.D. Rotstein. 1991. Effect of systematic fibrinogen depletion on intraabdominal abscess formation. J. Lab. Clin. Med. 118:48-55.

4. Tang, L., T.P. Ugarova, E.F. Plow, and J.W. Eaton. 1996. Molecular determinants of acute inflammatory responses to biomaterials. J. Clin. Invest. 97: $1329-1334$.

5. Wu, X., M.H. Helfrich, M.A. Horton, L.P. Feigen, and J.B. Lefkowith. 1994. Fibrinogen mediates platelet-polymorphonuclear leukocyte cooperation during immune-complex glomerulonephritis in rats. J. Clin. Invest. 94:928-936.

6. Marcus, A.J. 1994. Thrombosis and inflammation as multicellular processes: significance of cell-cell interactions. Semin. Hematol. 31:261-269.

7. Ross, R. 1993. The pathogenesis of atherosclerosis: a perspective for the 1990s. Nature (Lond.). 362:801-809.

8. Davie, E.W., K. Fujikawa, and W. Kisiel. 1991. The coagulation cascade: initiation, maintenance, and regulation. Biochemistry. 30:10363-10370.

9. Altieri, D.C. 1995. Proteases and protease receptors in modulation of leukocyte effector functions. J. Leukocyte Biol. 58:120-127.

10. Tordai, A., J.W. Fenton II, T. Anderson, and E.W. Gelfand. 1993. Functional thrombin receptors on human T lymphoblastoid cells. J. Immunol. 150: 4876-4886.

11. Molloy, C.J., J.E. Pawlowski, D.S. Taylor, C.E. Turner, H. Weber, M. Peluso, and S.M. Seiler. 1996. Thrombin receptor activation elicits rapid tyrosine phosphorylation and stimulation of the Raf-1/MAP kinase pathway preceding delayed mitogenesis in cultured rat aortic smooth muscle cells. Evidence for an obligate autocrine mechanism promoting cell proliferation induced by G-protein-coupled receptor agonists. J. Clin. Invest. 97:1173-1183.

12. Grandaliano, G., A.J. Valente, and H.E. Abboud. 1994. A novel biologic activity of thrombin. Stimulation of monocyte chemotactic protein production. J. Exp. Med. 179:1737-1741.

13. Sower, L.E., C.J. Froelich, D.H. Carney, J.W. Fenton II, and G.R. Klimpel. 1995. Thrombin induces IL-6 production in fibroblasts and epithelial cells. Evidence for the involvement of the seven transmembrane domain (STD) receptor for $\alpha$-thrombin. J. Immunol. 155:895-901.

14. Sitrin, R.G., R.F. Todd III, H.R. Petty, T.G. Brock, S.B. Shollenberger, E. Albrecht, and M.R. Gyetko. 1996. The urokinase receptor (CD87) facilitates CD11b/CD18-mediated adhesion of human monocytes. J. Clin. Invest. 97:19421951.

15. Rao, N.K., G.-P. Shi, and H.A. Chapman. 1995. Urokinase receptor is a multifunctional protein. Influence of receptor occupancy on macrophage gene expression. J. Clin. Invest. 96:465-474.

16. Gyetko, M.R., R.F. Todd III, C.C. Wilkinson, and R.G. Sitrin. 1994. The urokinase receptor is required for human monocyte chemotaxis in vitro. J. Clin. Invest. 93:1380-1387.

17. Gasic, G.P., C.P. Arenas, T.B. Gasic, and G.J. Gasic. 1992. Coagulation factors $\mathrm{X}, \mathrm{Xa}$, and protein $\mathrm{S}$ as potent mitogens of cultured aortic smooth muscle cells. Proc. Natl. Acad. Sci. USA. 89:2317-2320.

18. Ko, F.N., Y.C. Yang, S.C. Huang, and J.T. Ou. 1996. Coagulation factor $\mathrm{Xa}$ stimulates platelet-derived growth factor release and mitogenesis in cultured vascular smooth muscle cells of rat. J. Clin. Invest. 98:1493-1501.

19. Bouchard, B.A., M.A. Shatos, and P.B. Tracy. 1997. Human brain pericytes differentially regulate expression of procoagulant enzyme complexes comprising the extrinsic pathway of blood coagulation. Arterioscler. Thromb. Vasc. Biol. 17:1-9.

20. Bouchard, B.A., C.S. Catcher, B.R. Thrash, C. Adida, and P.B. Tracy. 1997. Effector cell protease receptor-1, a platelet activation-dependent membrane protein, regulates prothrombinase-catalyzed thrombin generation. $J$. Biol. Chem. 272:9244-9251.

21. Ambrosini, G., and D.C. Altieri. 1996. Molecular dissection of effector cell protease receptor-1 recognition of factor Xa. Assignment of critical resi- 
dues implicated in antibody reactivity and ligand binding. J. Biol. Chem. 271: 1243-1248.

22. Nicholson, A.C., R.L. Nachman, D.C. Altieri, B.D. Summers, W. Ruf, T.S. Edgington, and D.P. Hajjar. 1996. Effector cell protease receptor-1 is a vascular receptor for coagulation factor Xa. J. Biol. Chem. 271:28407-28413.

23. Ambrosini, G., J. Plescia, K.C. Chu, K.A. High, and D.C. Altieri. 1997. Activation-dependent exposure of the inter-EGF sequence $\mathrm{Leu}^{83}-\mathrm{Leu}^{88}$ in factor Xa mediates ligand binding to effector cell protease receptor-1. J. Biol. Chem. 272:8340-8345.

24. Cirino, G., C. Cicala, M. Bucci, L. Sorrentino, J.M. Maragonore, and S.R. Stone. 1996. Thrombin functions as an inflammatory mediator through activation of its receptor. J. Exp. Med. 183:821-827.

25. Damas, J., and G. Remacle-Volon. 1986. Mast cell amines and the oedema induced by zymosan and carrageenans in rats. Eur. J. Pharmacol. 121: 367-376.

26. Altieri, D.C. 1995. Xa receptor EPR-1 FASEB (Fed. Am. Soc. Exp. Biol.) J. 9:860-865

27. Esmon, C.T. 1993. Cell mediated events that control blood coagulation and vascular injury. Annu. Rev. Cell. Biol. 9:1-26.

28. Nystedt, S., K. Emilsson, C. Wahlestedt, and J. Sundelin. 1994. Molecular cloning of a potential proteinase activated receptor. Proc. Natl. Acad. Sci. USA. 91:9208-9212.

29. Appella, E., E.A. Robinson, S.J. Ullrich, M.P. Stoppelli, A. Corti, G. Cassani, and F. Blasi. 1987. The receptor-binding sequence of urokinase: a bio- logical function for the growth-factor module of proteases. J. Biol. Chem. 262: 4437-4440.

30. Plescia, J., and D.C. Altieri. 1996. Activation of Mac-1 (CD11b/CD18)bound factor $\mathrm{X}$ by released cathepsin $\mathrm{G}$ defines an alternative pathway of leukocyte initiation of coagulation. Biochem. J. 319:873-879.

31. Tannenbaum, S., H. Oertel, W. Henderson, and M. Kaliner. 1980. The biologic activity of mast cell granules. I. Elicitation of inflammatory responses in rat skin. J. Immunol. 125:325-335.

32. Galli, S.J., and B.K. Wershil. 1996. The two faces of the mast cell. Nature (Lond.). 381:21-22.

33. Kanwar, S., and P. Kubes. 1994. Mast cells contribute to ischemia-reperfusion-induced granulocyte infiltration and intestinal dysfunction. Am. J. Physiol. 267:G316-G321.

34. Zimmerman, G.A., T.M. McIntyre, and T.M. Prescott. 1992. Endothelial cell interactions with granulocytes: tethering and signaling molecules. Immunol. Today. 13:93-100.

35. Asako, H., I. Kurose, R. Wolf, S. DeFrees, Z.L. Zheng, M.L. Phillips, J.C. Paulson, and D.N. Granger. 1994. Role of H1 receptors and P-selectin in histamine-induced leukocyte rolling and adhesion in postcapillary venules. $J$. Clin. Invest. 93:1508-1515.

36. Kubes, P., and S. Kanwar. 1994. Histamine induces leukocyte rolling in post-capillary venules. A P-selectin-mediated event. J. Immunol. 152:35703577. 